\title{
A CONTRIBUIÇÃO DA FRATERNIDADE PARA O ENFRENTAMENTO DO DESASTRE REPRESENTADO PELA PANDEMIA DA COVID-19
}

\author{
Adelaide Elisabeth Cardoso Carvalho de França ${ }^{1}$ \\ Clara Cardoso Machado Jaborandy ${ }^{2}$ \\ DOI: https://doi.org/10.47306/978-65-88213-03-2.327-341
}

Sumário: 1 Introdução; 2 Saúde como direito/dever e como bem comum da humanidade; 3 a contribuição da fraternidade como recurso hermenêutico no contexto da pandemia da covid19; 4 Consideracões finais; Referências.

\section{Introdução}

Ao longo da história, os desafios da humanidade no seu caminho evolutivo, tem se valido da Fraternidade, em suas diversas categorias para encontrar soluções eficazes, seguras e eficientes.

Contemporaneamente, em contexto histórico definido como pós-modernidade, em meio a uma complexa organização de relações políticas, sociais e econômicas em âmbito globalizado, toda a espécie humana se vê diante de um novo desafio, representado não mais pela personificação de ideais ou distorções éticas e morais estigmatizantes, mas pela ameaça invisível de um vírus com grande potencial de contaminação e letalidade.

Trata-se do surto da doença causada pelo novo coronavírus (COVID-19) primeiro identificado, em Wuhan na China, em Dezembro de 2019, que pode causar diversos sintomas, sendo o mais grave o desenvolvimento de doença respiratória grave e morte.

Após ocasionar as primeiras mortes e se espalhar rapidamente em nível global, a Covid-19 foi, primeiro, declarada como Emergência de Preocupação Internacional, em 30/01/20 - o mais alto nível de alerta da Organização Mundial de Saúde, conforme previsto no Regulamento Sanitário Internacional (RSI) ${ }^{3}$ e em 11 de março de 2020, a COVID-19 passou a

\footnotetext{
${ }^{1}$ Mestre em Direitos Humanos pela Universidade Tiradentes. Graduada na Universidade Federal de Sergipe. Advogada da União. Email: adelaide.carvalhodefranca@gmail.com.

${ }^{2}$ Doutora e Mestre em Direito pela Universidade Federal da Bahia. Professora do Mestrado em Direitos Humanos da UNIT. Lider do Grupo de pesquisa Direitos Fundamentais, novos Direitos e evolução social. Advogada. Email: claracardosomachado@gmail.com.

3 Regulamento Sanitário Internacional (RSI) foi internalizado em território nacional por meio do Decreto Legislativo 395/2009 (UNIÃO, 2009).
} 
ser caracterizada pela OMS como uma pandemia e até 13 de junho de 2020 contava com 7.410.510 casos confirmados e 418.294 mortes no mundo (ONU, 2020).

Esses números demonstram a gravidade da situação ora posta a ponto de suscitar o enquadramento como desastre biológico, tanto pela intensidade espelhada pelos números de mortos e atingidos, como também pela instabilidade sistêmica representada no ordenamento brasileiro pela decretação de Estado de Defesa pela União, Estado de Emergência ou de Calamidade, por Estados e Municípios (CARVALHO, 2020).

Os impactos causados pela pandemia da COVID-19 já podem ser sentidos nos sistemas político, econômico, jurídico e sanitário, para citar alguns, que demandam respostas para o enfrentamento em meio a um cenário nebuloso em que estudos científicos para definir tratamentos e medidas de contenção ainda não são conclusivos, gerando assim uma miscelânea de informações (verdadeiras, erradas e fabricadas).

Propõe-se a compreensão do direito à saúde como bem comum da humanidade, cuja proteção e garantia de sua efetividade só pode ser alcançada pela cooperação entre o Estado e a coletividade nacional e internacional a partir da instituição de deveres.

Será proposta a revisitação da Fraternidade a partir de seus fundamentos, traduzidos na revelação da essência humana, reconhecimento do outro e no dever de ação para encontrar soluções adequadas que contemplem o enfrentamento da pandemia da Covid-19 na busca de gerir riscos e impactos sobre a sociedade em geral

Sob perspectiva metodológica, lança-se mão do método hipotético-dedutivo, a partir da revisão bibliográfica nacional e estrangeira com natureza aplicativa na identificação de ações que expressam a Fraternidade no ambiente normativo como jurisprudencial.

\section{Saúde como direito/dever e como bem comum da humanidade}

Antes de discorrer sobre a saúde como bem comum da humanidade é necessário compreender o que se entende por saúde tanto no aspecto normativo como no social. Para tanto, deve-se utilizar como ponto de partida o preâmbulo da Constituição da Organização Mundial de Saúde (OMS) que define saúde como "estado de completo bem-estar físico, mental e social e não consiste apenas na ausência de doença ou enfermidade" (OMS, 1946).

A Constituição da OMS destaca que a saúde é um direito humano de caráter universal, sem distinção de raça, religião, credo político ou condição econômica ou social. A importância 
da saúde é tamanha que sua proteção pelos Estados Membros é fundamental para conseguir a paz e a segurança.

Ademais, outro aspecto que merece ser evidenciado na Constituição da OMS é que o “desigual desenvolvimento em diferentes países no que respeita à promoção da saúde e combate às doenças, especialmente contagiosas, constitui um perigo comum" (OMS, 1946).

O tratamento desigual no combate a COVID 19 pelos Estados Membros, por exemplo, traz um perigo para toda a humanidade, razão pela qual urge a defesa da saúde enquanto bem comum da humanidade sendo imperiosa sua tutela jurídica e social tanto internamente quanto internacionalmente.

Sem que aqui se pretenda aprofundar o debate em toda a sua extensão, o que seria inviável em face das limitações espaciais de um artigo, é mister verificar o tratamento jurídico dado à saúde no plano internacional e nacional.

O programa das Nações Unidas para o Desenvolvimento estabeleceu os Objetivos do Desenvolvimento Sustentável (ODS) estabelecendo metas para cumprimento até 2030, também conhecida como Agenda 2030. A Agenda 2030 prevê, no objetivo 3 que os Estados devem "assegurar uma vida saudável e promover o bem-estar para todos, em todas as idades". O objetivo 3 foi subdividido em 13 metas. A meta 3.8 estabelece "Atingir a cobertura universal de saúde, incluindo a proteção do risco financeiro, o acesso a serviços de saúde essenciais de qualidade e o acesso a medicamentos e vacinas essenciais seguros, eficazes, de qualidade e a preços acessíveis para todos." (ONU, 2015).

A Organização Mundial de Saúde (OMS), ao idealizar o Plano Global de Ação para Vidas Saudáveis e Bem-Estar para Todos em setembro de 2019, buscou implementar estrategicamente as metas relacionadas a saúde em cumprimento ao Objetivo de Desenvolvimento Sustentável n. 3.

Para tanto foram convocados quase todos os organismos do sistema das Nações Unidas: a OMS, Aliança Global para Vacinas e Imunização (Gavi), Onu Mulheres, Banco Mundial, Programa Mundial da Alimentos (PMA), Fundo das Nações Unidas para Infância (Unicef), Fundo das Nações Unidas para Populações (Unfpa), Programa Conjunto das Nações Unidas sobre HIV/Aids (Unaids), Global Financing Facility (GFF), Global Fund, Programa das Nações Unidas para o Desenvolvimento (Pnud), Unitaid.

Recentemente, a Comissão Interamericana de Direitos Humanos, em especial atenção à desigualdade em que se encontra as Américas, em sua Resolução 1/2020 (CIDH, 2020) estabeleceu que: 
A pandemia da COVID-19 pode afetar gravemente a plena vigência dos direitos humanos da população em virtude dos sérios riscos que a doença representa para a vida, a saúde e a integridade pessoal, bem como seus impactos de imediato, médio e longo prazo sobre as sociedades em geral e sobre as pessoas e grupos em situação de especial vulnerabilidade.

E adiante realça a natureza jurídica do direito à saúde como um bem público:

[...] que deve ser protegido por todos os Estados e que o direito humano à saúde é um direito de caráter inclusivo, que guarda correspondência com o gozo de outros direitos, que compreende seus determinantes básicos e sociais como o conjunto de fatores que condicionam seu efetivo exercício e gozo; que o conteúdo do direito à saúde se refere ao direito de toda pessoa a desfrutar do mais alto nível de bem-estar físico, mental e social; e que este direito inclui a atenção à saúde oportuna e apropriada, bem como os elementos essenciais e inter-relacionados de disponibilidade, acessibilidade, aceitabilidade e qualidade dos serviços, bens e instalações de saúde, inclusive os medicamentos e os benefícios do progresso científico nesta área, em condições de igualdade e não discriminação.

Vê-se, portanto que a saúde é um bem essencial para o indivíduo e para a coletividade, que encontra forte aproximação com o direito à vida digna, ao trabalho, à moradia, à alimentação, entre outros direitos, na medida em que a saúde precisa ser assegurada em sua integralidade.

As ações do Estado e dos indivíduos em relação à saúde devem ter como meta o bem comum, que é o bem de uma comunidade. Inelutavelmente, a razão da existência de uma comunidade é a busca pelo bem comum e, por isso, a promoção e proteção da saúde deve ter como base o bem da própria comunidade. Nesse sentido, aduz Possenti:

Con l'idea di bene comune non si rincorre il mito romantico di una comunità perfettamente solidale e armoniosa, ma un concetto che è vitale per l'intera filosofia pubblica e la cui assenza la rende inintelligibile. Conduciamo un esperimento mentale: si provi a cancellarne l'idea e si verifichi se sussistano ancora motivi perché gli uomini vivano insieme. Essi potranno forse ancora stipulare contratti privati, ma non esisterà più una società politica, perché non vi sarà più un bene globale intenzionato dai "cittadini" e che su essi rifluisce. Se non vi fosse un bene comune da raggiungere, la società non esisterebbe. (POSSENTI, 1991, p. 67).

O bem comum, na perspectiva tomista é aquele que é capaz de abarcar a comunidade política inteira. Para Aquino a noção de bem comum é o ponto central da sociedade e do governo e é a partir dele que é possível ordenar uma comunidade de cidadãos. Trata-se, portanto, de um bem da ordem. (BARZOTTO, 2009)

Para além de um bem da comunidade a saúde deve ser compreendida como bem comum da humanidade na medida em que a humanidade tem sido ameaçada de destruição pela irresponsabilidade e falta de cuidado dos seres humanos.

Leonardo Boff e Miguel de Escoto ao redigir o esboço da Declaração Universal do Bem Comum da Terra e da Humanidade pontuaram do artigo 7 que:

São Bens Públicos da Humanidade as energias necessárias para a vida, a saúde e a educação, os meios de comunicação, a internet, os correios e os transportes coletivos. 
Os medicamentos produzidos por laboratórios privados passam a pertencer ao Bem Comum da Humanidade depois de cinco anos e, em situações de emergência, podem ser tornados públicos imediatamente.

De fato, ao se pensar numa perspectiva global não há como deixar de reconhecer que saúde é um bem comum da humanidade fato que demanda do Estado e da sociedade uma postura proativa no sentido de sua promoção e proteção.

No sistema constitucional brasileiro a saúde é tratada como direito/dever ao ser elencada no artigo $6^{\circ}$ enquanto direito social e ao prescrever no art. 196 que saúde é direito de todos e dever do Estado, ressaltando a obrigação precipuamente estatal na promoção desse direito.

Em verdade, é dever de todos em corresponsabilidade com o Estado, uma vez a construção de uma sociedade fraterna depende não só do Estado prestador e garantidor de direitos, mas também de indivíduos comprometidos com uma cidadania ativa e inclusiva que reconheçam seus deveres em prol do bem-estar social e da comunidade, admitindo-se, inclusive, limitações ao exercício dos direitos fundamentais. (MACHADO, 2017).

Nesse sentido, a efetivação de políticas públicas relacionadas à saúde depende da cooperação dos cidadãos para alcançar um consenso decisório quanto aos rumos a serem perseguidos a bem da coletividade. Para ratificar esta assertiva, sublinha-se o entendimento de Sandra Regina Martini, no tocante à efetivação do direito à saúde:

Para efetivar uma política de saúde adequada, é necessário que os atores envolvidos
nela participem do processo desde sua gestão até sua implementação. É neste sentido
que o direito à saúde pode ser resgatado e efetivado, pois não basta dizer que a saúde
é um direito do cidadão e um dever do estado, é preciso criar condições para que este
direito seja efetivado, e isso se dará somente por meio de políticas públicas que
respeitem as diferenças loco-regionais, mas que apresentem uma estrutura global, pois
os problemas de saúde não são territorialmente limitados. (MARTINI, 2009).

No mesmo sentido, Dallari (1998, p. 330) destaca o caráter coletivo do direito à saúde ressaltando a possibilidade de o Estado por meio de leis definir comportamentos nocivos passíveis de serem sancionados.

Compreendendo a saúde enquanto direito/dever cumpre verificar a atribuição da saúde enquanto bem comum da humanidade de modo a defender sua proteção para além dos limites do Estado e, assim, reconhecer a existência de deveres específicos a serem observados pelo Estado e pela sociedade para sua plena efetivação, cumpre observar a contribuição da Fraternidade para o enfrentamento do desastre sanitário representado pela pandemia da COVID-19. 


\section{A contribuição da fraternidade como recurso hermenêutico no contexto da pandemia da covid-19}

Longe de ser um evento isolado os desastres apresentam-se como estímulos que têm a capacidade de desenvolver um processo de "auto-irritabilidade" em sistemas diversos independente da sua origem natural, tecnológica ou híbrida mas têm em comum a destruição, a perda e em alguns casos a irreversibilidade. (DAMACENA, 2012)

Délton Winter de Carvalho (2020) enfatiza que o elemento caraterizador da pandemia como desastre subjaz na sua capacidade de comprometer outros sistemas determinando um "cataclisma" de causas que assumem consequências catastróficas, com especial ênfase ao sistema de saúde pública mundial:

Note-se inevitável, aqui também, considerarmos a Pandemia causada pelo novo
coronavírus como um verdadeiro desastre, tendo este desencadeado uma
desestabilização social sistêmica, o que redundou em decretações generalizadas (em
nível nacional, estadual e mesmo municipal) de Situação de Emergência e de Estado
de Calamidade. Apenas para fins de exemplo de tal situação destacam-se a declaração,
em nível federal, de Emergência em Saúde Pública e do Estado de Calamidade
Pública.

Essa vulnerabilidade expõe a atual situação da sociedade como dependente não apenas de um Estado vigilante e paternalista que planeja e conduz os desafios que se apresentam, mas da compreensão da necessária associação de muitos atores, para resignificar a gestão das ações necessárias para a superação de desastre da proporção de uma pandemia, afastando-se assim, por sua ineficiência óbvia, todas as opções que apontem soluções de uma maneira individualizada e sob os princípios do homus economicus.

Ainda que a pandemia ponha no plano de igualdade toda a sociedade, considerando apenas a sua humanidade, os seus efeitos danosos são mais sentidos por alguns, por aqueles que se apresentam sem a possibilidade de poder proteger-se melhor em razão da vulnerabilidade sócio-econômica em que já se encontravam.

Não sem razão afirma Herrera Flores (2009, p. 231) que a existência de desigualdades impede que todos tenham acesso a condições materiais e imateriais concretas que consolidam uma existência digna, é também a razão de uma era marcada por direitos, mas também por deveres consolidados na exigência de reconhecimento e respeito, na responsabilidade de todos e de cada um.

Para proteger o individuo de situação de desastre tal como a apresentada pela pandemia é imprescindível primeiro constatar que a excepcionalidade da situação determina a 
imperiosa adoção de medidas integrativas a suprir as lacunas do ordenamento jurídico, tal como destaca Délton Winter de Carvalho (2020):

Neste processo de integração, desencadeado pela configuração de um evento social como desastre, o Direito dos Desastres irradia aos demais ramos o cumprimento conjunto de diversas funções tais como:

(i) manter a operacionalidade do Direito, assegurando sua habilidade de operar de acordo com os seus padrões de regras, procedimentos, rotinas e protocolos;

(ii) lutar contra a ausência de Direito, pois nos desastres há a necessidade de que seja assegurada uma rápida atuação acerca das possíveis violações jurídicas nas comunidades atingidas por eventos graves;

(iii) fornecer estabilização e reacomodação, devendo as vítimas serem abrigadas e, dependendo da gravidade do evento, serem permanentemente realocadas;

(iv) promover a identificação das vítimas e responsáveis;

(v) e finalmente, reduzir a vulnerabilidade futura, mediante os processos de aprendizagem com os eventos passados e as experiências bem-sucedidas.

Nessa interação sistêmica é possível observar que a Fraternidade tem muito a contribuir, posto que rechaça previamente a ideia de relações hierarquizadas, para colocar-se na posição de irmãos, que extraindo o conteúdo teológico do significado originário da Fraternidade, simbolicamente materializa a equalização dos atores, ainda que uma eventual situação de carência os distinga. Os atores, “irmãos”, portanto, responsabilizam-se reciprocamente pela sorte de ambos.

Sob a fórmula de "solidariedade intensa" (PIZZOLATO, 2008), a Fraternidade se apresenta como uma relação que se estabelece entre duas pessoas em um mesmo nível de identificação horizontal, com reconhecimento universal e inclusivo, determinando uma constante interpelação do comportamento individual para a responsabilização pela sorte de todos.

Diferentemente da Solidariedade que se reporta às intervenções próprias do Estado Social, para a superação das desigualdades sociais por meio de ações públicas expressas em benefícios sociais, a Fraternidade remete aos deveres que lhe são decorrentes, exigindo a atuação coordenada e paralela dos concidadãos e do Estado, na garantia de fruição de direitos que visam essencialmente a proteção do gênero humano. Esses direitos, referenciados como Direitos de Fraternidade são identificados notadamente por sua natureza difusa ou transindividual, entre eles o direito ao socorro humanitário em casos de desastres. (MACHADO, 2017, p. 61)

A Fraternidade se traduz pois, nos seguintes fundamentos primordiais: na revelação da essência humana, no reconhecimento do outro e no dever de ação.

O primeiro, relaciona-se com a possibilidade de distinguir a essência humana, consubstanciada na ideia da "autoconsciência do homem como é e deve ser" referenciada por Miguel Reale (1975, p. 192), e dissociada da simples aparência, que aliada apenas às 
características físicas do ser, prescinde de qualquer demonstração ${ }^{4}$. A essência humana necessita da ação na presença do outro para se desvelar. (FRANÇA, 2019)

É inegável que na busca de recompor estabilização social dos efeitos da pandemia é necessária a adoção de diversas medidas de amplo espectro para proteger o gênero humano. E estas serão tão mais eficientes se for garantido a todos o acesso universal a atenção médica necessária para o tratamento das doenças decorrentes da pandemia da Covid-19, desprezando os dados característicos que servem para marcar a nacionalidade, situação legal no país, orientação sexual, grupo étnico e especialmente a idade.

Dessa maneira as autoridades públicas devem se comprometer a enfrentar a pandemia em respeito aos valores que dignificam a pessoa humana, velando pela proporcionalidade, necessidade e precaução quando a situação determine eventual restrição a liberdade, imposta pelo isolamento social para retardar a propagação do vírus, garantindo à população o livre acesso à informação segura e eficaz.

Também se depreende do agir fraternalmente o compromisso da sociedade global no fortalecimento dos mecanismos de cooperação técnica internacional que permitam o compartilhamento dos avanços das pesquisas científicas desenvolvidas, processos tecnológicos no desenvolvimento de insumos médicos e farmacêuticos necessários para o tratamento da população doente.

Por outro lado, ciente de si como ser humano é possível reconhecer no seu semelhante igual adjetivo e com ele se emparelhar de forma a estabelecer uma relação fraterna permeada por ações recíprocas de reconhecimento, representado pela estima social que possibilita o indivíduo referir positivamente sobre si e às suas capacidades concretas, além de potencializar as dos demais, rechaçando todas as forma de desrespeito, expresso em de maus tratos (rebaixamento pessoal), na privação de direitos (rebaixamento moral) ou na desvalorização de suas características e capacidade pessoais (rebaixamento social) ${ }^{5}$. E nessa proposição é possível observar o segundo fundamento da Fraternidade: o reconhecimento do outro.

\footnotetext{
${ }^{4}$ Essa perspectiva é descrita na seguinte análise de Maria Inês Chaves de Andrade: "Uma sociedade de homens não é necessariamente uma sociedade humana. Dito dessa maneira, põe-se que o homem nem sempre é humano se sua essência não se revela. Se não há o outro para que a humanidade se conforme entre seres fraternos, não temos uma humanidade, mas uma comunidade de homens iguais a si mesmos, individualmente indeterminados porque a nenhum há o outro para que a essência lhes diga quem são e o que contêm em si. Ser simplesmente homem sem que haja a fraternização com o outro não há como dizê-lo ser humano, mas puramente homem. Ser homem não é ser nada, mas saber em si."

${ }^{5}$ Conforme Axel Honneth (2003) o desrespeito é representado pelo reconhecimento recusado, como expressão de um comportamento lesivo pelo qual as pessoas são feridas na compreensão de si mesmas, diferenciando as três formas de rebaixamento: os maus tratos práticos; o que afeta o auto respeito moral, e o que afeta negativamente o valor social de indivíduos ou grupos.
} 
A partir desse fundamento, define-se a atuação prioritária das medidas necessárias de enfrentamento da pandemia, tomando em consideração a vulnerabilidade como condição que qualifica indivíduos, grupos e contextos em que vivem, e que influenciam na sua capacidade de antecipar, lidar e resistir a um determinado desastre, seja ele oriundo de causas "naturais" ou não. (DAMACENA, 2012)

Reconhecer a vulnerabilidade do outro, importa em desnaturalizar a situação de pobreza e extrema pobreza em que está mergulhada boa parte da população latino-americana que enfrenta dificuldades para ter acesso a água potável, moradias hígidas, saneamento básico, que garanta a adesão de todos às medidas sanitárias até então identificadas como a utilização de máscaras, isolamento social e higienização constante das mãos.

E por fim o terceiro fundamento da Fraternidade pode ser apontado como sendo a sua razão prática, no direito de ser humano, realçando a ação e o dever ser humano que impõe a observância da lei, perscrutando a realização do ser humano no seu máximo ético. (ANDRADE, 2010).

Nessa mesma linha, Clara Machado (2017, p. 126) aponta que a Fraternidade impõe ao indivíduo a responsabilidade com sua comunidade a qual coincide com o "imperativo ético" de Hans Jonas (2006, p. 47-48) que a todos é exigível o dever de "agir de modo a não prejudicar nem colocar em risco a existência das gerações futuras. "

Marco Aquini (2008, p. 138-139), de igual forma, ao enunciar a paridade entre os sujeitos ressalta que dela advém a "responsabilidade fraternal". Essa compreensão leva necessariamente a estender o rol de "responsáveis" para a promoção do desenvolvimento e pelo dever de cooperação, na medida que alberga todos, em nível nacional e internacional, sem com isso desonerar as autoridades públicas na implementação das políticas públicas que lhe cabem originariamente.

Samuel Pufendorf (2007, p. 163) ao descrever os deveres do homem e do cidadão de acordo com as leis do Direito Natural enfatiza o imprescindível liame entre os indivíduos na promoção de suas capacidades e desenvolvimento da comunidade que não se satisfaz com a inação:

Entre os Deveres de um Homem para com o outro que devem ser praticados pelo bem da Sociedade Comum, colocamos em terceiro lugar este: Que todo homem deveria promover o Bem de outro, na medida em que ele convenientemente puder. Pois toda a Humanidade foi feita pela Natureza, por assim dizer, uns aparentados com os outros; essa Relação exige mais do que meramente abster-se de causar mal e dar Desprezo aos outros. Não é, portanto suficiente que nós não magoemos, nem desprezemos nossos Semelhantes, mas devemos também prestar aos outros, ou comunicar mutuamente Aqueles bons ofícios que permite o Amor fraternal comum ser mantido 
entre os Homens. Ora, podemos ser benéficos para o nosso Próximo ou definida ou indefidamente; e isso significa, nós próprios abrindo mão de alguma coisa ou nada. ${ }^{6}$

A Declaração Universal dos Direitos Humanos (ONU, 1948) reconhece no seu preâmbulo, o valor diretivo da Fraternidade ao afirmar no seu art. $1^{\circ}$. que a dignidade é inerente a todos da família humana, determinando assim o dever de todos agirem em relação uns aos outros com espírito de fraternidade, o qual se traduz na dimensão comunitária dos deveres prevista no art. 29 que preceitua que "todo ser humano tem deveres para com a sua comunidade, na qual, unicamente livre e o pleno desenvolvimento de sua personalidade é possível".

Esse dever de Fraternidade impulsiona a todos ao enfrentamento da crise sanitária representada pela COVID-19 num cenário de catástrofe para adoção de medidas de prevenção, mitigação e recuperação a fim de fazer frente a desestabilização social sistêmica, que irradia e retroalimenta as causas e efeitos policontextuais (econômicos, políticos, jurídicos, científicos) (CARVALHO, 2020).

Sob a perspectiva econômica a reconfiguração que determina o dever de Fraternidade se expressa na absorção das estruturas humanistas para qualificar a liberdade e igualdade de modo a construir suporte para a conformação de novo modelo em prol da humanidade, capaz de legitimá-lo, ao tempo que permita a correção das causas que criam vulnerabilidades, e que favoreçam a sua superação.

Tal modelo econômico foi apontado por Sayeg e Balera (2011) como sendo Capitalismo Humanista ${ }^{7}$ caracterizado precipuamente pela observância dos Direitos Humanos e pela efetividade da dignidade da pessoa humana, por meio do qual a sociedade civil e o homem livre são supletivamente responsáveis no que tange a concretização multidimensional dos direitos humanos, notadamente em tempos de estagnação econômica.

Esta semente lançada ao vento há quase uma década, vem apresentando seus frutos. $\mathrm{O}$ mais recente, se expressa na decisão proferida nos autos do processo 102746560.2020.8.26.01006, 22 ${ }^{\mathrm{a}}$ Vara Cível do Foro Central de São Paulo (Tribunal de Justiça de São Paulo, 2020) na qual um restaurante firmou cédulas de crédito bancário a ser pago em doze parcelas variáveis, apesar de estar cumprindo com o pactuado, requereu ao Poder Judiciário a concessão de tutela antecipada para que fosse autorizada a suspensão temporária dos pagamentos das prestações ajustadas, bem como a liberação das garantias prestadas ao Banco,

\footnotetext{
${ }^{6}$ Destaque no original.

${ }^{7}$ O Capitalismo Humanista tem encontrado eco no Poder Legislativo por meio da proposta de Emenda Constitucional 383/2014, e da Proposta de Emenda à Lei Orgânica do estado de São Paulo 04-00001/2014, que foi aprovada em primeiro turno, mas carece de ratificação em segundo turno.
} 
em virtude da quarentena imposta como medida sanitária para evitar maior disseminação do coronavírus. A tutela de urgência foi concedida, na qual o juiz destacou:

\begin{abstract}
A respeito, revela-se imperioso acrescentar, à guisa de elucidação, que o caso fortuito ou força maior exclui a responsabilidade da parte que não deu causa ao seu advento, consoante preceitua o artigo 393 do Código Civil in verbis: 'O devedor não responde pelos prejuízos resultantes de caso fortuito ou força maior, se expressamente não se houver por eles responsabilizado. ' Evidente que, quando da celebração das operações enumeradas na exordial, o autor não tinha como prever o advento de uma pandemia dessa envergadura que iria atingir em cheio sua atividade econômica, praticamente paralisando-a; é neste momento que o Estado deve atuar para fins de equilibrar as relações jurídicas em geral, no sentido de, de forma proporcional e razoável, conforme alude o artigo oitavo do CPC, no caminho de salvaguardar o interesse público, evitar maiores e profundos prejuízos a todos, mormente àqueles que se mostram mais vulneráveis na relação jurídica estabelecida, nos termos dos preceitos que devem orientar a relação jurídica de consumo, de acordo com o normatizado pelo artigo $4^{\circ}$. do Código de Defesa do Consumidor.
\end{abstract}

Essa decisão segue a lição proferida pelo Ministro Moura Ribeiro, quando também desempenhava o cargo de Desembargador do Tribunal de Justiça de São Paulo ao julgar a Apelação n. 991.06.054960-3 (BRASIL, Acórdão no 991.06.054960-3, 2010) que the rendeu inclusive a indicação ao Prêmio Nobel da Paz (BRASIL. Aplicação do capitalismo humanista inspira indicação do ministro Moura Ribeiro ao Nobel da Paz. 2020).

Naquela oportunidade, esteve sob seu julgamento a execução promovida por uma instituição bancária em razão do atraso no pagamento das mensalidades convencionadas com uma família que se tornou inadimplente em razão de uma doença grave que acometeu o filho. Aplicando a prevalência do direito fundamental e humano à vida, afastou a culpa decorrente de caso fortuito, explicando que:

Toda-regra jurídica imposta aos homens não se baseia no respeito e na proteção do
direito individual, que não existem, e de uma manifestação de vontade individual, que
por si mesma não produz efeito social algum, mas na solidariedade da estrutura social,
como observam ARAKEN DE ASSIS, RONALDO ALVES DE ANDRADE e
FRANCISCO GLAUBER PESSOA ALVES.
Por derradeiro, não se pode afirmar a mora dos devedores porque diante do elemento
externo imprevisível, ou acudiam as necessidades do filho doente, ou pagavam o
mútuo hipotecário.
Optaram e bem, pela primeira hipótese, até porque a Constituição Federal assegura,
sem nenhuma restrição ou condição, o direito à vida (art. $5^{\circ}$, caput).

Em outra oportunidade, o Tribunal de Justiça de São Paulo materializando a Fraternidade para solução o conflito entre direitos reais no contexto da pandemia da COVID19 destacou a prevalência da dignidade da pessoa idosa para obstar a imissão de posse em imóvel penhorado em ação indenizatória, flexibilizando a norma civil para atender a eficácia horizontal dos direitos fundamentais. (BRASIL. 2020. Decisão n. 2020.0000337435 AGT).

Tais ponderações representam alguns passos que o Judiciário promove na constituição de uma sociedade fraterna, cuja urgência se faz sentir ainda mais no contexto de crise. 


\section{Considerações finais}

A persistir na invisibilização dos flagelos da sociedade pós moderna que justifica a estranheza ou mesmo a surpresa do destino comum de toda a humanidade não se poderá avançar de maneira eficiente.

Em contraposição a essa ordem que determina o fracasso da trajetória da espécie humana propõe-se a revisitação da Fraternidade que impulsiona a necessária cooperação entre todos, a nível global e interno para a efetividade do direito à saúde como bem comum.

No contexto do desastre sanitário evidenciada pela pandemia da COVID-19 imperiosa a adoção de medidas compartilhadas que determinem a assistência aos grupos vulneráveis e revitalizem o Direito a partir de recursos hermenêuticos adequados aos fundamentos da Fraternidade para superar a crise sistêmica determinada pelos efeitos nocivos identificados não apenas pelo eclipse do sistema de saúde mas na contaminação também de outros sistemas como econômico, social e político .

Expressam os deveres de Fraternidade as medidas que favoreçam o acesso universal a prestação de serviço de saúde, que proporcionalmente avaliem a necessidade de restrição a liberdade imposta pelo isolamento social para retardar a propagação do virus, a garantia do direito à informação segura, verdadeira e eficaz. Além daqueles que se aplicam em âmbito internacional que derivam do compromisso de cooperação entre os povos com o compartilhamento dos avanços científicos alcançados na busca de uma vacina ou terapias comprovadamente eficazes.

Aliam-se às medidas operacionais para gestão da crise, os projetos de lei e emenda constitucional que promovem a observância dos direitos humanos em ambiente capitalista, bem como a absorção desses ideais pelo Judiciário.

Grandes avanços estão sendo observados que revelam que muito mais que altruísmo. A Fraternidade, como categoria jurídica, oferece recursos hemenêuticos ao Direito para garantir a sua operacionalidade sem se desviar de seu objetivo maior que é a garantia de uma vida digna.

\section{REFERÊNCIAS}

ANDRADE, Maria Inês Chaves de. A Fraternidade como direito fundamental entre o ser e o dever ser na dialética dos opostos de Hegel. Coimbra: Edições Almedina Ltda, 2010.

AQUINI, Marco. Fraternidade e Direitos Humanos. In: O Princípio esquecido: A Fraternidade na reflexão atual das ciências políticas. Tradução de Durval Coradas, Iolanda 
Gaspar e José Maria de Almeida. Vargem Grande Paulista: Editora Cidade Nova, 2008, p. 138-139.

BARZOTTO, Luiz Fernando. O Bem da Ordem - O Direito como Condição da Moral em Tomás de Aquino. In: STOCK, A. C. \& LISBOA, W. B. (org.). Norma, Moralidade e Interpretação: temas de Filosofia Política e do Direito. Porto Alegre: Linus, 2009.

BUONOMO, Vicenzo. Vínculos relacionais e modelo de fraternidade no direito da Comunidade Internacional. In: O Princípio Esquecido/2: Exigências, recursos e definições da fraternidade na política. Traduções Durval Cordas, Luciano Menezes Reis. Vargem Grande Paulista-SP: Cidade Nova, 2009.

BRASIL . Decreto Legislativo 395/2009 publicado no DOU de 10/07/09, pág.11. Disponível em:

http://portal.anvisa.gov.br/documents/375992/4011173/Regulamento+Sanit\%C3\%A1rio+Inte rnacional.pdf/42356bf1-8b68-424f-b043-ffe0da5fb7e5. Acesso em 20.05.2020.

BRASIL. Tribunal de Justiça de São Paulo. Acórdão n 991.06.054960-3. Relator: Desembargador Moura Ribeiro. São Paulo, Data de publicação: 30 de setembro de 2010. Disponível em:

http://www.stj.jus.br/sites/portalp/SiteAssets/documentos/noticias/Aco\%cc\%81rda\%cc\%83o \%20Des.\%20Moura\%20Ribeiro\%20TJSP.pdf. Acesso em: 29 mar. 2020.

BRASIL. Superior Tribunal de Justiça. Aplicação do capitalismo humanista inspira indicação do ministro Moura Ribeiro ao Nobel da Paz. Publicação em 19/02/2020. Disponível em: http://www.stj.jus.br/sites/portalp/Paginas/Comunicacao/Noticias/Aplicacaodo-capitalismo-humanista-inspira-indicacao-do-ministro-Moura-Ribeiro-ao-Nobel-daPaz.aspx. Acesso em: 20 mar 2020.

BRASIL. Tribunal de Justiça do Estado de São Paulo. Decisão n 1027465-

60.2020.8.26.0100. Relator: Juiz Mario Chiuvite Júnior. São Paulo, Data de publicação 31 de março de 2020. São Paulo. Disponível em: https://www.conjur.com.br/dl/suspensaopagamentos-restaurante.pdf. Acesso em: 15 maio 2020.

BRASIL. Tribunal de Justiça do estado de São Paulo. Decisão n. 2020.0000337435 AGT (2044946-28.2020.8.26.0000SP), Relator: Alfredo Attié. São Paulo Data de publicação 13/05/2020. Disponível em: https://jurisprudencia.s3.amazonaws.com/TJ-SP/attachments/TJSP_AGT_20449462820208260000_035a0.pdf?Signature=blkAkepY\%2FCesbOcONdXr1B6 $\mathrm{qv} \% 2 \mathrm{FI} \% 3 \mathrm{D} \&$ Expires $=1591838569$ \&AWSAccessKeyId=AKIARMMD5JEAO765VPOG\&r esponse-content-type=application/pdf\&x-amz-meta-md5-

hash=6f0e2cc27123365325860b051fc27f16. Acesso em: 10 jun 2020.

CARVALHO, Délton Winter. A natureza jurídica da pandemia COVID-19 como um desastre biológico: um ponto de partida necessário para o Direito, Revista dos Tribunais, n. 1017, julho 2020, prelo.

COMISSÃO INTERAMERICANA DE DEIREITO HUMANOS -CIDH. Resolução no 1/2020. Aprovada em 10 de abril de 2020. Disponível em:

https://www.oas.org/pt/cidh/decisiones/pdf/Resolucao-1-20-pt.pdf. Acesso em: 22 maio 2020. 
DAMACENA, Fernanda Dalla Libera. A formação sistêmica de um Direito dos desastres. Dissertação de Mestrado. São Leopoldo. 2012. Disponível em: http://biblioteca.asav.org.br/vinculos/tede/FernandaDamacenaDireito.pdf. Acesso em: 20 maio 2020.

DALLARI, Sueli Gandolfi. Uma nova disciplina: o direito sanitário. Revista de Saúde Pública, São Paulo, v. 22, n. 4, 1988. Disponível em: https://www.scielo.br/pdf/rsp/v22n4/08.pdf. Acesso em 07 jun 2020.

FLORES, Joaquim Herrera. A reinvenção dos direitos humanos. Florianópolis, Fundação Boiteux, 2009.

FRANÇA, Adelaide Elisabeth Cardoso Carvalho de, O Pluralismo jurídico na América Latina: a emergência de uma proposta paradigmática a partir da Fraternidade. Dissertação de Mestrado. Aracaju, UNIT, 2019.

JONAS, Hans. O princípio responsabilidade: ensaio de uma ética para a civilização tecnológica. Trad. Marijane Lisboa, Luiz Barros Montez. Rio de Janeiro: Contraponto: ed. PUC-Rio. 2006.

MACHADO, Clara. O princípio Jurídico da Fraternidade. Um instrumento para a proteção de direitos fundamentais transindividuais. Rio de janeiro: Lumen Juris, 2017.

MARTINI, Sandra Regina; OLIVEIRA, Christiano Augusto Seckler de. O direito à saúde e os determinantes sociais. Revista da Defensoria Pública, ano 1, n. 1, jul/dez 2008. Edição Especial Temática sobre Direito à saúde, v. 2, p. 284-285.

MARTINI, Sandra Regina. Saúde: um direito fundado na fraternidade. In: Fundação Oswaldo Cruz, Núcleo de Estudos em Direitos Humanos e Saúde Helena Besserman. Saúde e direitos humanos, ano 5, n. 5 (2008). Brasília: Editora do Ministério da Saúde, 2009.

MARTINI, Sandra Regina. Diritto fraterno, movimenti sociali e Beni comuni a tutta l'umanità: chi è il proprietário se el bene è di tutti?. Stato e diritti nell'età della globalizzazione. Salerno: Brunolibri, 2010, p. 71- 89.

ONU, Declaração Universal dos Direitos Humanos. 1948. Disponível em: https://nacoesunidas.org/wp-content/uploads/2018/10/DUDH.pdf. Acesso em 15 maio 2020.

ONU, Folha informativa - COVID-19 (doença causada pelo novo coronavírus) in: https://www.paho.org/bra/index.php?option=com_content\&view $=$ article\&id=6101:covid19\&I temid $=875$. Acesso em 20.05.2020.

PIZZOLATO, Felipe. A Fraternidade no ordenamento jurídico italiano. In: O Princípio esquecido: A Fraternidade na reflexão atual das ciências políticas. BAGGIO, Antônio Maria (org.). Tradução de Durval Coradas, Iolanda Gaspar e José Maria de Almeida. Vargem Grande Paulista: Editora Cidade Nova, 2008.

PUFENDORF, Samuel. Os deveres do homem e do cidadão de acordo com as leis do direito natural. Rio de janeiro: Liberty Fund, 2007. 
REALE, Miguel. Filosofia do Direito. V. 1, 7. Ed., São Paulo: Saraiva, 1975, p. 192.

SAYEG, R. H.; BALERA, W. O capitalismo humanista: filosofia humanista de direito econômico. Petrópolis: Ed. KBR, 2011. 